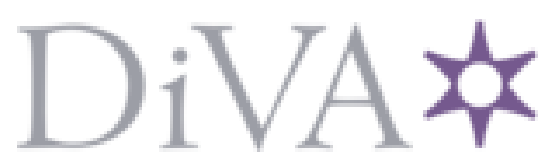

http://www.diva-portal.org

\title{
Postprint
}

This is the accepted version of a paper published in Narrative Inquiry. This paper has been peerreviewed but does not include the final publisher proof-corrections or journal pagination.

Citation for the original published paper (version of record):

Bülow, P., Hydén, L-C. (2003)

In dialogue with time: identity and illness in narratives about chronic fatigue.

Narrative Inquiry, 13(1): 71-97

http://dx.doi.org/10.1075/ni.13.1.03bul

Access to the published version may require subscription.

N.B. When citing this work, cite the original published paper.

Permanent link to this version:

http://urn.kb.se/resolve?urn=urn:nbn:se:hj:diva-5623 
IN DIALOGUE WITH TIME: IDENTITY AND ILLNESS IN NARRATIVES ABOUT CHRONIC FATIGUE

Pia H. Bülow and Lars-Christer Hydén

Department of Communication Studies

Linköping University

Linköping, Sweden 


\begin{abstract}
When we are stricken with an illness or some other affliction, the temporal frameworks that we take for granted in our everyday lives are overturned. Thus suffering and illnesses raise questions associated with temporality: were the past events necessary and unavoidable, could anything else have happened, and what will happen next? In this article we will discuss two intertwined problems that have to do with the organization of time in narratives about illness: the interviewee's attempt to create an interview narrative and the researcher's need to create a temporal order and coherence in the interview material properly founded in research. With a foothold in the literary scholars Morson's and Bernstein's theories about shadows of time we base our argument on an analysis of narratives given in interviews by people affected by Chronic Fatigue Syndrome (CFS). The analysis shows various ways time can be used as a discursive tool to temporalize illness and suffering including temporalities that frequently go outside linear time perceptions by the use of "sideshadowings". These various ways of temporalizing illness influence, for instance, factors like issues of responsibility and freedom of action. Findings like these indicate the importance of including the interviewees' own temporalizations in the analysis of illness narratives in social science.
\end{abstract}

Keywords: illness narratives, interviews, narrative analysis, responsibility, temporalization 
INTRODUCTION: THE PROBLEM OF TIME IN INTERVIEW NARRATIVES

Every suffering and illness has a history - a past, a present, and a future. Thus suffering and illnesses raise questions associated with temporality: were the past events necessary and unavoidable, could anything else have happened, and what will happen next? When we are stricken with an illness or other affliction, the temporal frameworks that we take for granted in our everyday lives are overturned. Thus we have problems with one of the foundations for organizing our lives and ourselves, namely temporality. One way to make sense of and to order our life is by narrativizing our experiences of illness, a narrativization and temporalization which often is asked for by, for instance, consulted physicians and social researchers (Bury, 2001; Hydén, 1997).

The issue of time in suffering and illnesses is often brought to the fore in studies of experiences of illness and narratives about illness. In this article we would like to discuss a problem that we feel to be central specifically in studies of different forms of illness narratives that are based on use of interview material. Our thought is that we as researchers are confronted with two intertwined problems that have to do with time. The first is the interviewee's attempt in the interview situation to use time to create a narrative based on a balancing act between personal responsibility and liability, between hope and despair, and between the possible and the actual. The second is the interviewer's need to impose researchbased temporal order and coherence on the interview material. This means that there are at least two different kinds of temporal orders which are to be put together. There is therefore a risk that a certain temporal order - perhaps chiefly the researcher's - will dominate, at the expense of other possible temporal orders. The problem is that we are then in danger of losing the issues of responsibility for actions and destiny, possibility and necessity, which are linked to the sufferer's narrativization, and thus an action-related plurality that presupposes active use of a whole series of different temporal frameworks.

In our view, it is possible to shed new light on how time is used in interview subjects' narratives about their illnesses, based on discussions of temporality by two literary historians, Gary Saul Morson (1994) and Michael André Bernstein (1994). They examine examples from Russian literature (Morson) and narratives about the Holocaust (Bernstein), based on the idea that temporality concerns issues of conduct, freedom, determinism, responsibility, destiny, and choice. They are especially critical of the "utopian temporality [that] satisfies a hunger for certainty” (Morson, 1994, p. 1). It does not offer any opportunity of reflection or individual 
action, since life is seen as being predetermined by a temporal pattern that the individual cannot influence, but to which he or she must resign himself. By the same token, they say, there is a tendency in all sciences - social science, as well as the humanities and the natural sciences - to reduce time to one type of time, and thus to describe and perceive human existence within a framework that is far too narrow. Morson and Bernstein argue instead that we need "multiple concepts of time - multiple 'chronotopes', as Bakhtin would say - for diverse purposes and circumstances” (Morson, 1994, p. 3). We argue that their emphasis on the diversity of temporality - by their concept shadows of time - can provide new perspectives on studies of narratives about illness.

If, like Morson and Bernstein, we proceed from a view of time as being closely associated with central human questions concerning hope, guilt, blame, and regret, then the conception of time also becomes significant to how we interpret and thus narrate our own experiences, and to how we interpret others' narratives. While a research interview is a tool with which researchers collect data as well as an opportunity for the interviewee to try to describe and explain his/her experiences, it is also a meeting between two people who create an interview narrative together. Thus the significance and function of different temporalities that are used will influence this meeting and also the interpretation of what is told. And if a greater role is given to the different temporalities that are expressed in the interview, this should have implications for the analysis regarding factors like issues of responsibility and freedom of action.

There are two points that we want to make in this article. The first is to show how interview subjects use various forms of temporality for various purposes and the second is to argue for the importance of letting the narrator's temporalization of his or her illness narrative appear in the analysis. We start by discussing the general matter of time and narrative and the relation between narrativizing and temporalizing. After this an overview of how the issue of time and illness has been described and analyzed within social science will be presented, especially concerning studies of illness narratives. Then Morson’s (1994) and Bernstein's (1994) alternative for analyzing temporalizations as shadows of time is introduced, followed by our own study based on an analysis of narratives given in interviews by people affected by Chronic Fatigue Syndrome (CFS). By proceeding from what people tell about themselves and their illness, with a foothold in Morson's and Bernstein's theories, we attempt to describe the various ways time can be used as a discursive tool to tell about illness and identity - what we call temporalizing. 


\section{NARRATIVIZING AND TEMPORALIZATION}

All narration is based on our selection of certain events as "reportable” (Labov, 1972). Telling about these events can cast a special light on one’s life, for example, or on one's current situation (Bruner, 2001). The selecting of events, the organization of them and the description of the relationship between these events are thus basic elements in narratives. The construction of the order and the relationship between events involves asking questions about factors including the result of one's own action or lack of action, about necessity and externally-originating constraints, about what might have been possible but never occurred. It connects the way we choose and narrate events to issues that deeply affect our own moral evaluations of our lives. This is something that has the greatest significance especially in connection with illness (see, for example, Hydén, 1995; Williams, 1993).

Creating an inner order and relationship between events involves the narrator's use of time; events are organized within themselves, which is tantamount to some form of temporal relationship and order. If two events happen at different moments of time one thing has to be said to happen earlier and the other consequently occurs later (Fillmore, 1997). Thus we often visualize time as being linear; it moves in only one direction from the past to the future. Linear time is often compared to an arrow or an axis. This view, however, of time as merely linear has lately been rejected by social theorists like Barbara Adam (1995) and Alberto Melucci (1996), who both plead for a complexity of times (consisting of different aspects of time) and for a view of time as simultaneously linear and circular.

According to Jens Brockmeier's (2000) analysis of autobiographical narratives narrated time can also be given other forms than the arrow. Brockmeier states that "autobiographical time” from the straight line "only needs a small shift” to be ordered into a circle, a cyclical wave shape, or a spiral. Regardless of the linear time's form, it seems to give a time that moves "forward" with, as Freeman describes it," each moment unique and unrepeatable" (Freeman, 1998). As we know from fiction, temporality can, however, assume many forms; we have possible and virtual times, events that develop backwards, and so on. As narrators we are often adroit at using just these different forms for temporalization.

\section{ILLNESS AND TIME}

In research about illness experience and time it is, somewhat simplified, possible to identify three different ways that sufferers' temporalization of illness has been interpreted and analyzed. First, there are studies that are based on a linear comprehension of time, in which 
the illness is analyzed as a disruptive event that marks the temporal distinction between "before" and "after". Secondly, there are studies based on the same linear perception, but in which analyses primarily take the direction of time as departure. Thirdly, there are studies that build on the fact that there can be different types of temporal orders, and that interviewees and/or their narratives can conform to these temporal orders. We briefly discuss these different ways of interpreting and analyzing the temporalization of illness experience.

The first way, to describe illness, and primarily chronic illness, as an interruption - a "biographical disruption” is rather common in social science since the publication of Michael Bury’s (1982) well-known article. According to this view the medical diagnosis and the illness achieve the status of something that divides life into a "before" and an "after". For the individual this leads to the perception of a "disrupted life" (Becker, 1997) in which falling ill is a sort of "turning point” interviewees describe (Charmaz, 1991). That is, life is seen with a linear perception and the illness is therefore placed into that time line.

In the view of the illness as a disruption, it is the break and the gap between then and now that must be handled in some way. Narrating then becomes a question of creating a coherent life story bridging the gap between life before the illness and the life that the illness and the diagnosis involve. Williams (1984) describes in an often-cited article how narratives about chronic illness create such a coherence via a reconstruction of the life history - and thus of the individual identity - in which the then and the now are joined together. Mark Freeman (1993), the American psychologist who has been interested in the relationships between memory, narrative, and self, describes similarly how the retelling in the form of autobiographical texts is a kind of "rewriting the self".

Analyses which are limited in this way to linear time become problematical in understanding narratives that fall outside the culturally prevalent figure of time, i.e. when the narrator's temporalizing is not in linear order (or for that matter falls outside the researcher's choice of temporal direction). In Brockmeier's (2000) analysis, for example, this results in two categories of "timeless" models - what he calls "the static" and "the fragmentary" models - in which he describes the former as common when people tell about illness, bereavement, torture and other traumatic experiences. In Davies’ (1997) breakdown of her interviewees’ temporalizations, the category of "living in the empty present" similarly represents a way of temporalizing one's experiences that rejects the linear view of time by simply ignoring it. The same can probably be said about Charmaz' (1991) category "existing from day to day", and about Frank’s (1995) chaos narrative. 
The second way of analyzing temporality is likewise based on the linear time axis with the illness as a turning point and a disruption, which causes the issue of the temporalization's direction to appear. Time and the temporal dimensions are usually studied and analyzed in a forward direction from the present toward the future, or based on the question of how the present can be understood in light of the past. An example of the aforementioned is Charmaz' (1991) analysis of "how ill people’s thoughts, feelings, and actions toward [the present] shape their time structure and reshape their perspective” (p. 170). Asbring (2001) makes a similar description of CFS as a disruption in life that is handled in a forward direction. Similarly, several researchers have, after the recent development of new medicines for HIV-infected and AIDS patients, studied how people with these diagnoses regard their uncertain but more positive futures (Davies, 1997; Ezzy, 2000; Pierret, 2001) in the same kind of forward direction of time.

One interesting example of how illness and identity can be temporalized in different ways backward in time is brought out in an analysis by Orona (1990). She describes how people who care for an Altzheimers-afflicted spouse or parent use temporal dimensions in order to be able to understand their relative’s identity change, to describe a changed perception of time (compared with earlier), and to oppose the identity loss brought by the illness in order to retain memories of the relative as he or she was before the illness.

The problem with these analyses of temporality is that they exclude descriptions based on what could have happened, but did not happen, i.e. the trials and tests that the narrator can make of various possible courses of events and assumptions of responsibility in the past (for an example of this, see Hydén, 1995). Not allowing the past just to cast a shadow forward, but rather testing the possibilities of other courses of events, demonstrates the possibilities of the past.

The third way of analyzing the temporalization by sufferers is based on researchers' thinking in terms of a number of models for temporality and time sequence in which whole narratives are reduced to a certain type of illness narrative. Ezzy (2000) describes this as ”identifying the dominant narrative structure around which each interview was formed” (p. 608). Similarly, many researchers have identified and categorized different kinds of illness narratives that are formulated is relation to time (Charmaz, 1991; Davies, 1997; Frank, 1995; Orona, 1990; Pierret, 2001; Robinson, 1990). Robinson (1990), for example, using an analytic model developed by Gergen and Gergen (1986), described a number of different kinds of biographical narratives based on how people afflicted with MS employ written 
autobiographical accounts to formulate their illness narratives in relation to time and to their own goals.

The problem with typologically classifying narratives and categorizing them is that, in principle, it is only possible to describe one way in which the individual temporalizes his illness, while other types of temporalizations end up outside the analysis or remain unobserved. Thus the narrator is forced into one type of the researcher's gallery of types, and the hesitations and trials that may remain in the narratives risk being lost.

The problem of time, which we as researchers are confronted with, is connected with the interview and how we analyze it. In the interview situation two different temporal frames meet: the interviewer's and the interviewee's. Analyzing the interview later on the researcher adds a third temporal frame, namely the analytical/interpretative. In analyzing, writing and reading temporalizations in illness narratives it is sometimes difficult to distinguish between these three frames. This is sometimes found in the overview of research presented here as well. However, despite the different ways that interviewee's narrativizations about illness have been interpreted and analyzed few researchers have discussed the possibility of many different ways of temporalizing in a single illness narrative. Likewise few researchers have discussed what meaning the use of different kinds of temporalizations have in illness narratives. In order to be able to adopt a multiple view of temporality it is necessary that we as researchers use a broader concept of temporality. We need one that will give us the opportunity to ensure that interview subjects can use and alternate between different forms of temporality in their narratives and that these will be reflected in the analysis. For this, it is important to discuss and distinguish between different temporal frameworks for interview narratives. This means that it is of interest to us to search for authors who present analytical instruments that can shed light on different forms for temporalization. The Bakhtin tradition (Bakhtin, 1986), as it is presented by Morson (1994) and Bernstein (1994), is just such an interesting example.

\section{SHADOWS OF TIME}

Narrating and narratives can, by describing other times and other places, be seen as a way of transporting both the narrator and the listener in both time and space (Young, 1989). It can also be seen as a way to try to form the future by initiating a narration about what could happen (Mattingly, 1998). Morson (1994) and Bernstein (1994) attempted to describe different forms of temporalization. They worked, sometimes in parallel, with three different 
forms of temporalization which they call "shadows of time", based on the fact that they were particularly interested in the relationship between possibility and necessity in the novel and in historiography.

The concept shadows of time means that events cast their shadows over the narrator's present. These shadows of time can come from the front (foreshadowing), from the back (backshadowing), or from the side (sideshadowing). Based primarily on Russian literature (especially on Dostojevsky and Tolstoy), Morson (1994) describes how the shadow of what is expected to happen, what has happened, and what might happen - or even what might have happened, gains significance in the narrative of a novel in the use of different types of shadows that can open and close time.

Foreshadowing, or the shadow that future events cast over characters in films or novels without the character himself knowing what we as audience or readers think we understand, is hardly ever found in narratives of life experiences that people give in interviews. This is a sort of "backward causation" that, outside literature can almost exclusively be equated to a belief in omens as prospects of what will happen. However, to understand in retrospect how an event should have been foreseen in different signs and omens, which once something has happened are reinterpreted as signs of what later on actually did happen - "backshadowing" can very well be included in people's narratives about their lives. The shadow comes in both cases before the fateful or important event, but in the latter case could not be understood until afterwards, when something has already happened. Regardless of whether a catastrophe can be predicted ahead of time (as by the reader of a novel), or retrospectively is judged as something which should have been predicted, both the foreshadowing and the backshadowing presuppose a predestined event, something that cannot be changed. Time closes.

Morson (1994, p. 238) states that both of these two time shadows can be related to what is needed for "good storytelling". In other words, with these time shadows a more "tellable and effective" structure can be created, with a certain order between different events. "Loose ends” are eliminated, and a structure with a beginning, a middle, and an end becomes a narrative technique that we use almost "automatically”. What Morson calls "loose ends” consist of alternative courses of events and possibilities - "sideshadowing", shadows cast on the present from the sides. These "sideshadows" tell what could happen or what could have happened. Sideshadowing opens time. At the same time as a description is given of what happened, the picture of what could have happened becomes apparent. In sideshadowing, that which has happened becomes not the only possible outcome, but rather one of at least two 
possible alternative developments of events. Thus the sideshadows counteract the tendency to interpret what is happening now as an unavoidable consequence of earlier events. The sideshadows entice us instead to investigate "the other possible presents that might have been and to imagine a quite different course of events" (Morson, 1994, p. 118). Questions like "if only this or that had not happened, what would my life look like now; what would have happened?” become both possible and reasonable to ask.

A fourth time concept that Morson works with is vortex time - in other words, regarding time as a whirlpool or as a black hole. Vortex time is the opposite of sideshadowing - where sideshadowing divides itself into branches of a number of different courses of events, vortex time converges several different reasons and events into one single point, a catastrophe. Morson compares this to "a hidden clock [which] seems to synchronize this diversity so that, even though causal lines seem unrelated to one another, they not only lead to the same result but also do so at the same moment.” (p. 163).

Even though Morson and Bernstein developed their concepts of time shadows based on written fiction and historical novels in which a story always has some sort of an ending, we suggest that it is reasonable to use some of these concepts to describe and understand how interviewees tell about their illnesses. The concept of time shadows and the various ways of temporalizing make it possible to understand how interviewees tell how events have influenced their lives in different ways, how they could have influenced them, and even how they can influence them in the future. The shadows of time, and primarily sideshadowing, make a more open view of use of time possible, by presenting an alternative to the otherwise quite closed temporality that linear narratives have. This will be of our concerns when we now turn to the study and to the analysis of narratives about CFS.

\section{THE INTERVIEWEES AND THE ANALYSIS}

The examples that we will discuss are excerpts from interviews with 14 people, each of whom has received a diagnosis of CFS or a related diagnosis in which unexplained fatigue makes up a significant part of his/her suffering. These people earlier constituted two "classes" in a patient school organized by, and carried out at a specialist clinic in a large hospital in Sweden. After each class completed the patient school in which one of the authors of the article (PB) took part during an observation study (Bülow, 2002; Bülow \& Hydén, 2003), contact with several of the participants continued. 
Except for one person who was interviewed only once, all of the interviewees were interviewed on at least two different occasions, and half of these (seven people) were interviewed on a third occasion. All interviews lasted for about an hour. The first interview took place in most cases about six months after completion of the patient school. An additional period of between three months to a year elapsed between the two first interviews. The third interview was done with six subjects about $1 \frac{1}{2}$ years after completion of the patient school. The third interview of one of the subjects was done after a lapse of $2 \frac{1}{2} 2$ years after completion of the patient school. Most of the interviews were conducted in the interviewee's home while the rest took place in public places like libraries or cafés that the interviewee suggested or at the interviewee's work place. The analysis presented here is based primarily on the 14 initial interviews.

The interviews were transcribed using a sociolinguistic model for narrative analysis that is based on spoken-language, rhythmic markers represented in lines and stanzas (Gee, 1986, 1991). Each line is organized around one central "idea unit" in what Gee (1991) terms “argument”. Lines then tend to be clustered into series of lines that have a similar structure, concern the same topic or are matched in content. These series of lines, called stanzas, are “the basic blocks of extended pieces of discursive language” (Gee, 1991, p. 23). Important for the analysis is the prosodic use of language where, for example, the length of a pause tends to indicate the end of line, or, if it is a longer pause, a major transition like the end of story (Gee, 1986). This model thus allows analysis of both the narratives' content and structure. It expresses oral narratives in writing, making it possible to capture both the clearly defined stories with a distinct narrative structure and those parts of less-structured narratives that often occur in interviews (Mishler, 1999).

In a first analytic phase, the transcribed interviews were labeled according to the temporal placement that the narrator assigned to events and experiences. Thus it became apparent how the interviewees oscillate between different time perspectives in their narratives. They switched back and forth between the times before their illnesses, the times of searching for answers about the unexplained suffering, how their lives were going at present, and so on. The individual narratives or narration episodes were then analyzed with regard to how the interview subjects made use of various temporalizations of their illnesses and their suffering in their narratives. 


\section{THE INTERVIEWS AND TEMPORALITY}

Interviews can be said to make up a complex discursive event in which a whole series of different time perspectives are presented by the interviewee in such a way that it becomes possible for the listener (the interviewer) to draw conclusions about how these events were played out in real time - what is sometimes called the told (in contrast to "the telling order") (Goodman, 1981; Mishler, 1992). At the same time the interviewer can by his/her way of questioning suggest for instance a certain time as the starting point or as the endpoint for a narrative. What is said and narrated in interviews is thus based in the interview situation's here and now. The speakers sit opposite each other, in a focused situation (Goffman, 1961), which makes it necessary for both of them to relate to the time of the narration. In other words, when the speakers move to other times and places, each must indicate to the other what he is doing. Thus it becomes possible for the second speaker to move along with the first, and at the same time to gather the different pieces together into a temporal whole. Temporalizations of illness events are therefore based on the interview situation's here and now, which thus makes up one of the points over which a shadow is cast.

The common starting place and the initial question in all interviews in our study concerned the patient school where the researcher/interviewer had first met the interviewees. How did they come to the patient school, and what had caused them to be there? From a point that in most cases was about six months back in time, the interviews were then developed into narratives starting from several different junctures in the interviewees' lives.

The interviewee as narrator and the interviewer as questioner and listener created jointly the order of what was said in the interview. The interviewer's questions and interposed comments sometimes led a narrator to continue, or caused him/her to diverge in some other direction. At other times the interviewee seems to have continued with the story that he/she started before the question.

Even though the narration time is constructed simultaneously by the interviewee and the interviewer and is partly controlled by a series of assumptions, the interviewees temporalize their experiences, thoughts, and explanations about their chronic fatigue in several different ways. They talk alternately about things that have happened recently, and of things that happened many years ago - in their childhoods, or when they started working at a certain job. The narration time thus shifts both listener and narrator from the present to the past and back to the present, which at the time makes the narrative seem quite fragmented. 
By classifying the parts of the interview in the analysis by their temporal placement in relation to, for example, when the person became ill, when the diagnosis was made (or in some cases not made), and the "present", and by distinguishing the narration sequences, it becomes clear how the interview and the "telling order" are configured. The narratives in the interviews are not always concluded with a new question from the interviewer and a question from the interviewer does not always immediately initiate a narrative. Instead, a narration can be initiated as a digression from an answer to a question, and a narration that has been concluded can be followed by a new narrative episode that follows chronologically the latest story told. The new narrative can also digress, as explanation or insertion of what is told in a larger context.

\section{TEMPORALIZING CHRONIC FATIGUE}

By starting out from the narrative time and how time is used in the order that the narratives follow in the interview, it becomes possible to see how the interviewees try to understand and describe something about their illnesses and their lives by switching between different temporalizations. In our material the use of various types of temporalizations thus seems to reveal something about responsibility for the illness as well as freedom of responsibility. A similar situation is seen in their choices of where in their life narratives they place their illnesses.

In the following we will discuss how the interviewees in our material operate with four different types of temporalizations in their narratives about chronic fatigue. The first way of temporalizing presented is the turning point. This is followed by three ways of temporalizing that correspond to Morson's concept of backshadowing, vortex time, and sideshadowing. However, we did not find any instances of foreshadowing, which according to Morson (1994, p. 7) “appears as the most artificial” of literary devices. We will however come back to this in our discussions about the examples of backshadowing.

\section{Turning points}

Turning points, as the concept has been described by for instance Charmaz (1991) as a special kind of time marker, are also used by the interviewees in our material. According to the view that a person's life biography could be described as a linear time axis Charmaz explains how a meaningful chronology can be created by inserting several different events and situations "time markers"- on the linear time axis. For this a number of different kinds of time markers 
can be used to sort out and divide up life experiences but only certain significant events attain the status of "turning points" (Charmaz, 1991) or "existential coordinates" (Orona, 1990). What makes a time marker be also a turning point, says Charmaz, is that it does not just mark a point in a life biography, but that it constitutes a shift both in the sequence of events and in self-understanding. These are moments of what Aristotle in his Poetics called "peripeteia” (Nussbaum, 1986).

By constituting a shift the description of an event as a turning point divides time into a "before” and an "after", a past and a future. In the interview with one woman, here called Gwen, one such turning point is described in the following story where each line has been numbered and where the spaces indicate a new stanza.

\section{Example 1}

01 well, I was at $X$ Square

02 or maybe it was Y Plaza

03 and I was going to go up

04 and the escalator wasn't working. (I: mhm)

05 I had to walk up the escalator then to-

06 everyone else was walking, of course - everyone

07 you just do it. You walk up, right? (I: $\mathrm{mhm}$ )

08 But you see, I couldn’t.

(..)

09 I wasn't strong enough to walk up those stairs, y'know

10 I'd been rushing around and was carrying shopping bags and stuff.

11 And just that I would suddenly have to walk up a huge, long stairs

12 and it was just too much.

13 And then I understood that something was not quite right here. (I: mhm)

14 So then I began to think that something was wrong.

The story is told in connection with an episode in which Gwen is telling about the time she was diagnosed with CFS, a condition that she previously had been reading a little about. She thus frames her story about the turning point to be similar to the stories of other sufferers that she had been reading. Interpreted as that, this story is about the accuracy of the diagnosis she has got. What is important in our analysis at this moment however is to show how she by telling about a specific event (“I was at ...”), which she describes in considerable detail, 
forms a story that ends up with the point that this was a moment when she realized something new about herself and her fatigue. That is, the turning point. After presenting the scene (lines 1-4) she continues to describe the problem she is facing when the escalator does not work and that she will have "to walk up the escalator". She tells about how other persons present at that specific time acted in the situation (“everyone else was walking”), what she perceives to be the expected thing to do in such circumstances ("You just do it. You walk up, right?”) and then concludes the comparison by stating “(but) you see, I couldn't”. In the third stanza (lines 10-12) she takes a step back and explains the situation that after rushing around the challenge of having to walk up the escalator "was just too much". Finally the turning point becomes the coda (Labov, 1972) of the story by marking a shift in her self-understanding ("And then I understood that something was not quite right here”).

Several of the interviewees used this kind of temporalization to point out, as in the example above, a specific time when they first perceived their illness as something really wrong or when they got some important answers like a diagnosis and a name for their illness. These events became turning points since they marked a shift in how the interviewees interpreted their illness.

\section{Backshadowing}

When the illness is viewed from the common point in time - the present - that the interview constitutes, significant events like being diagnosed or suddenly experiencing fatigue as illness are possible points of departure, or even, as in Example 1, described as turning points. However, this kind of time markers is far from the most obvious points that the interview subjects choose to expose. In the initial question about what made them come to the patient school, as well as during the rest of the interview, the interviewees often related their illnesses and suffering to other times, situations, and events which unlike turning points were more vague. In these descriptions the diagnosis or being taken ill suddenly does not form a clear break between a "before" and an "after". Instead the illness is depicted as something that revealed itself far earlier, but was perhaps not comprehended clearly at that early stage. What the interviewees describe is the shadow of what became the illness, rather than the actual illness. The shadow is one that the interviewee him/herself did not perceive as a sign of illness or even of approaching illness at the point of time at which it occurred. In retrospect, however, and in the light of what has happened up until now, these events, vague symptoms, 
and other experiences seem to be interpreted by the teller as signs that the interviewee him/herself or (sometimes) others should have understood much earlier.

When John (Example 2), at the start of the interview is asked about how he got to the patient school and how it all started his answer becomes a long story. However, almost immediately he interrupts himself and takes his story back to a much earlier time.

\section{Example 2.}

01 Well, it started out that I about-

02 or to be honest it was really so that I felt a little of that fatigue for many many years, actually.

03 But it sort of sneaked up on me

04 and it really wasn't really so eh it wasn’t so dramatic at that time.

05 I really went to the doctor a few times for that but-

06 And they did like in outpatient care then, at my family doctor's and such those quick examinations.

07 And they couldn’t find anything wrong really so

08 And then I felt a little better about it

09 and just continued on

10 even though I still had the fatigue

11 and it came and went sort of in waves, but

12 So it was really about ten years ago that I first felt it.

13 But um then about two and a half years ago now,

14 I- so um then I had a little increase in the fatigue

15 um and I guess I thought it was just another of those little periods again

16 that I'd had earlier like that

The story that John chooses to begin with concerns a time quite long before his diagnosis of CFS and even before an acute illness that he later on describes as the starting point of an extended medical inquiry. Instead of using a clear time marker he starts to tell about a time that continued for "many many years" (line 2). It is a time which is rather vaguely described as "at that time" (line 3) and which beginning later on in an "evaluative clause" (Labov, 1972) is settled as "about ten years ago" (line 12). Even though John emphasizes that he "really" had gone to his doctor for his fatigue, he also tells how he accepted the answers he received and "felt a little better about it". The symptom of fatigue sneaking up on him wasn't interpreted as especially alarming either by John or by the health care system. In the light of 
what happened after that - his falling suddenly ill and then having a residual, increased fatigue - his earlier fatigue is interpreted in a different way. In retrospect the period of fatigue that started about ten years earlier becomes a sign - a shadow - of the illness that appeared later. It was, however, a shadow that he didn't notice at the time. He didn't even perceive it as a shadow when the fatigue became accentuated shortly before his acute illness. At that point he interpreted it as being "just another of those little periods again” (line 15). At the time of the interview, however, the time shadows are very evident to him. This can be seen in the way John introduces his earlier fatigue as an important part of his illness narrative, even though it reflects a time long before his falling suddenly ill and long before the diagnosis was made, "or to be honest it was really so...”.

Time shadows like the one John is telling about in Example 3, which do not become evident until afterwards - backshadowing - means that not only experiences in the past can be reexamined, but also actions. In the interview with Tina (Example 3), she describes her life situation as she remembers it from the time when she began to feel ill. Her narrative develops successively between the interviewer's questions. In describing her work as rather stressful, she tells about negative changes in the organization of work, and also about her ambition to do a good job as well as about the feeling of responsibility that partly stopped her from "getting out of there". How her working situation, in combination with her "personality", had an effect on her and on the illness that developed later, she summarizes with the words:

\section{Example 3.}

Because that I really should have seen much earlier.

And left.

When Tina reflects on the time before and during her falling ill and of the stresses that eventually led to her illness breaking out she too uses a kind of backshadowing. The illness thus becomes a given result of her life as she has lived it. It is a shadow that she in retrospect thinks that she "should have seen much earlier" and also should have acted upon by leaving. Considering both John's story and Tina's the shadow of the future illness is made up not only of early signs of the disease in the form of symptoms, but can also be memories of traumas, life crises, or periods of intensive burdens that in retrospect can be understood as "omens" of illness and suffering. However, since it cannot be perceived ahead of time, it cannot be prevented but rather becomes something unavoidable. Yet backshadowing by no means implies freedom from responsibility but rather poses questions about responsibility and about whether alternative actions might have been possible. This relationship between 
foreshadowing and backshadowing is reflected in Bernstein's (1994, p. 16) description of backshadowing as a kind of "retroactive foreshadowing". That is, what seemed to be impossible to foresee becomes in retrospect something that should have been foreseen. Thus backshadowings seem to have to be handled within the narrative that discloses them as in the case of John declaring that that he in fact "went" to a doctor to check on his fatigue. By this statement as well as the one describing how he trusted the medical examinations which did not indicate any disease, he presents himself as a person who already at that time he is telling about showed great responsibility, which counteracts some of the questions that might be posed about possible actions. In a similar way what Tina tells about her feelings of responsibility towards her work might be interpreted as an answer for why no action was taken; why she did not leave.

\section{Vortex time}

A special way to explain and coordinate events backward in time is to relate them to each other, and to show in one's narration how several episodes and events that are separated in time and space finally converge at the point that something like a chronic diagnosis can be. This corresponds to what Morson (1994) calls "vortex time”. He describes vortex time as relentless and as ineluctable. In being likened to a whirlpool, vortex time appears to be an inverted variant of Brockmeier’s (2000) "spiral model” of autobiographical time. In contrast to Brockmeier's spiral, however, which directs itself outward in ever-widening circles, vortex time is not based on one single time line. It can rather consist of a whole series of different events that do not necessarily need to be related to each other but nonetheless converge in a central point. It is this centripetal, center-seeking force that characterizes vortex time and that distinguishes it from ”pure” backshadowing.

In the interview with Gwen a series of different narratives from different times in her life form a totality by converging in, or linking together in the illness as an unavoidable result of many different events in her life story. Gwen herself initiates the longer narrative without any new question being posed, when she reflects about her life with the words, "but a lot has happened, too/.../ there's a lot, I think, that this is due to”. After that she begins to tell about a series of different episodes having to do with her growing up, her husband's death, the development of a new family, tensions between generations, and problems in relationships with the children. The narratives are each concluded with a kind of refrain in which Gwen declares that "this isn't what has brought on this (CFS), but a lot has gone on in my life". 
After telling about a series of different events that she in a similar way declares cannot be said to have caused her chronic fatigue, Gwen summarizes these narratives about her life and the relentless unavoidable movement toward the illness (Example 4).

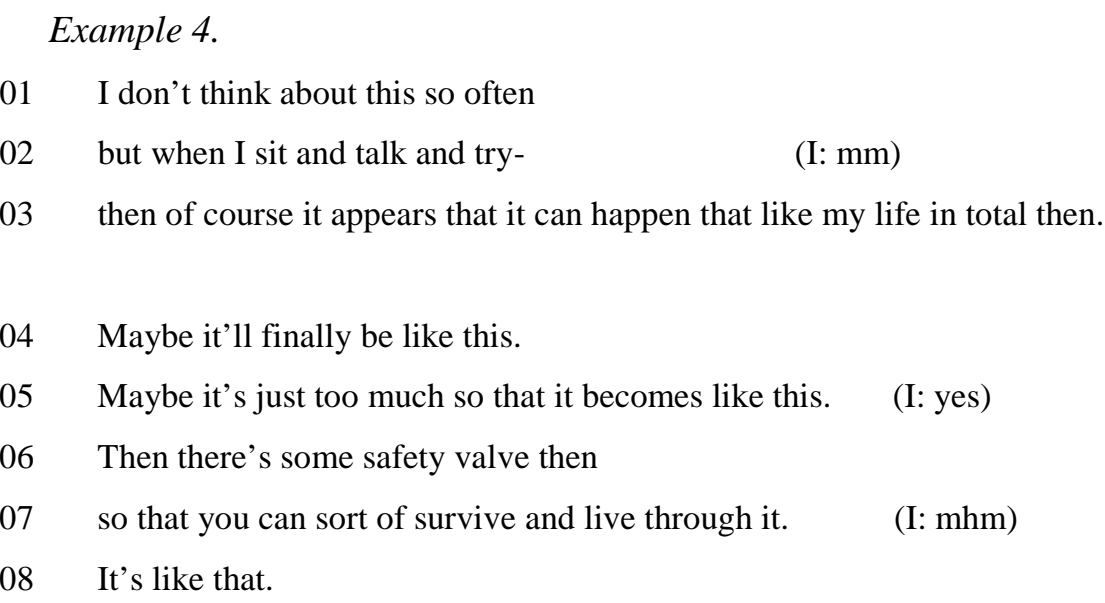

The ineluctable, what simply will "finally be like this", that Gwen in her narration calls a "safety valve" is described there as a result of what has happened in her life "in total". It was a series of different events that in themselves did not cause her illness, but which in combination converged in a fixed point - i.e. the chronic fatigue. The structure of vortex time is seen both in Gwen's summation of her narratives (Example 4) and in a narrative structure in which several events come together via the common refrain. The result of vortex time does not become evident until afterwards. In this case it is similar to backshadowing. Compared to the discussion in relation to backshadowing however, the structure of vortex time does not seem to raise any questions about responsibility and thereby does not in the same way call for accounts for not foreseeing the catastrophe. Unlike what was shown for backshadowing the refrain Gwen repeats after each single event she tells about stresses that this particular event or experience could not be blamed for causing the illness. That is, she could not have prevented the coming catastrophe by acting differently. This freedom of liability might be explained by the structure where the ineluctable consists of many different, unrelated but still concurrent working events that are connected in vortex time become almost impossible to see through. Not until afterwards when in these narratives the illness is a fact, will the vortex pattern appear.

The feeling of catastrophe brought on by the relentlessness in vortex time can to some extent be compared to what Arthur Frank (1995) calls "chaos narrative”. But in contrast to the anti-narrative structure and the non-self-reflecting trait that Frank describes for the chaos narrative, a narrative from vortex time involves a reflection in which earlier events and 
experiences are associated with illness and suffering that appeared later. Despite this difference, some of the interviews contain narratives that, observed from the narrative time, describe experiences in vortex time. However, in these the narrator still does not have the ability to describe any connections between different events by, for instance, converging in one central point. These narratives seem chaotic (to both the narrator and the listener), both because there is a lack of conceivable explanations for a narrated event and because the narration contains a structure in the form of vortex time. In this vortex time events are added to each other and thus appear to drag the person toward the catastrophe (the illness) and yet reject this kind of explanation. By not relating the events in time, these narratives are more similar to chaos narratives and to the type of timeless model for autobiographical time that Brockmeier (2000) calls the static model.

\section{Sideshadowing}

The exact opposite of vortex time is constituted by shadows from the side - sideshadowing which instead of indicating a single point gives an image of several different alternative courses of events (Morson, 1994). By opening time sideshadowing thereby also oppose the closure of backshadowing and foreshadowing.

By restoring the presentness of the past and cultivating a sense that something else might have happened, sideshadowing restores some of the presentness that has been lost. It alters the way we think about earlier events and the narrative models used to describe them. (Morson, 1994, p. 7)

That which might have happened and that which perhaps can happen is compared to a shadow from the side in Morson's concept of time shadows. It is a shadow that opens the door for other alternative courses of events both in the past and in the future. In Morson's analysis, he states that Dostojevsky, for example, who frequently employed sideshadowing, used the opposites of sideshadowing and vortex time to create effects in his narratives, and to make it possible to conclude his fictional narratives despite the open time he aimed at.

When Jenny (Example 5) tells, like Gwen in Example 4, about the combinations of reasons she sees to explain the chronic fatigue syndrome that afflicts her, the narrative does not stop at the inevitability (and the vortex time) where it starts. Jenny includes in her narration what also could have happened. 


\section{Example 5.}

01 But then I think it was a combination of um partly that I was already rundown before from lack of sleep, a lot of infections,

02 and then one serious infection that I then never recovered from (I: $\mathrm{mm}$ )

03 and then eh that eh job

04 and the stress.

05 And I think that I could have managed each of those factors

06 If it had been the only one. (I: $\mathrm{mm}$ )

07 If I had been in great shape and worked that much then it might have been OK.

08 Or if I'd just been sick but didn't have to work so much. $\quad$ (I: mm)

09 .h and then the lack of sleep I think too

10 I think lack of sleep effects people more than you understand

11 But then I guess there's also an inherited component.

12 That it's- eh but I mean If I'd been- if I'd had another inherited component

13 Maybe I would've had a heart attack instead.

14 I mean now I'm very young for a heart attack

15 but of course it- it could have been that instead. (I: mm)

16 But then I got this.

The two opposite-acting time shadows of vortex time and sideshadowing are both found in Jenny's narration. When the relentless and, because of the conditions of her life, inevitable result in the form of fatigue has been fully described as a sort of vortex (lines 1-4), Jenny switches to sideshadowing by opening the door to a series of other alternative courses of events (lines 5-8). In lines 9-11 however, she switches back to adding things to the list of difficulties that she believes have contributed to her illness. But then in line 12-15 she goes back to sideshadowing one of these (“if I’d had another inherited component”) before she closes by ascertaining what her "fate" has been. As a result her story is not just about what did happen and why but also about what might have happened. If the conditions at different junctures had been different, then something else could have been the result. The sideshadows that Jenny uses concern several different possible courses of events, which in part could have led to a completely different illness (like a heart attack) or in part didn't have to lead to any illness at all. If she had had to confront each of the stress factors by itself, then she might not have become ill. By opening the door to other possibilities, Jenny opposes the inevitable result that the series of different stress factors she described earlier seems to lead to, at the 
same time as she accepts what has happened. The shadows from the side do not allow the only possibility to stand unopposed, but weigh in many others.

Including sideshadowing in narratives about experiences of illness and suffering means often that the narrator is stating the conditions for events in an "if only" model (Morson, 1994), expressing wishes, thoughts, and assumed possibilities in statements like "if only ... then this could have happened", "if not only ... then it might have been OK”. In the example above it is obvious how Jenny switches in her sideshadowing from the indicative mode in past tense to describe how something was ("I was already run down”), to a subjunctive mode: "If it had been the only one”; "If I had been in great shape”; "if I had just been sick".

Even without explicitly expressing what might have happened if this or that had not occurred, or if this or that had not been the case, sideshadowing is a way to open up time. Sometimes in our material sideshadowings occur in the way a narrative is told about things that have happened. By for instance telling about dead ends a story almost automatically includes sideshadowing represented by all that might have happened if the way had not been blocked. This kind of unspoken sideshadowings occur, for example, in descriptions of the individual path to a diagnosis. Different diagnoses involve different courses of illness, and therefore different time images. To be confronted with many different possible diagnoses, as is the case for many who suffer from unspecified symptoms, therefore also includes being confronted with different pictures of the future and of time. Without explicitly discussing what could have happened if another diagnosis had been made, or if the diagnosis had been made on another occasion, the narratives about the different alternatives that have been blocked in various ways still make up a kind of sideshadowing of what could have happened. As Morson (1994) writes, it is telling about what happened that makes the picture of what could have happened become obvious.

Thoughts and reflections about the future also operate as a kind of sideshadowing in which a possible route is determined. However, it is not described as the only possible one but rather as one of several plausible continuations. Viewing the future as a special type of sideshadowing causes neither the future nor the time up to the interview to form a single long line. A cluster or a braid of different future threads is created instead; these can all materialize, but can just as easily remain what could have happened ”if only....”.

Including sideshadowing in a life narrative involves entering a dialogue with time and operating with various possibilities. In oral narration, hypothetical narratives (Riessman, 
1990) and narrating "in the subjunctive mode” (Bruner, 1986; Good \& Good, 1994) can be examples of ways to present sideshadowing. Labov (1982) discusses how adult storytellers often use "evaluative clauses" to tell about events that did not occur rather than those that did. However, according to David Herman (1999) these evaluative clauses tend to be regarded as comments on the evolving story and not as a part of it. Herman argues, just as we do about timeshadows, that these kinds of evaluations are important for the understanding of the narrative and thus has to be included in the analysis of the story. The tension that Mishler (1992) describes between on-line choices and off-line choices about profession and career can for instance show how people handle choices retrospectively and thus use a kind of sideshadowing when they tell about their lives. Certain events and choices can be seen as sidesteps that might have led to a completely different story than the one now being told. The life narrative thus becomes a more open story, in which the players are given responsibility for the events and choices presently being made.

\section{CONCLUSION}

Telling about one's chronic illness often involves an attempt to understand the origin of the illness in a life perspective, and as Williams (1984) describes it, to "reconstruct one's life narrative" so that the illness can be seen in the light of, and be explained by what happened earlier in life. However this might, as we have mentioned, involve the question about responsibility. In our analysis based on Morson's and Bernstein's concept of shadows of time we have shown how the interviewees use both time markers as turning points and different kinds of time shadows to tell about their chronic fatigue. These two kinds of temporalizations are however, as the analysis shows, rather different in their significance and function. Unlike turning points, whose function as significant time markers simply implies that specific events are marked out on a time line, time shadows bring to the narrative a depth by allowing time to be hazy and by the use of shadows cast from many different directions. This vagueness connected to time shadows makes them very usable in illness narratives, especially concerning the origin of the illness and questions about responsibility.

For the person who has a contested diagnosis like chronic fatigue, it appears that the affliction does not only lead to a reconstruction of the life narrative in the perspective of earlier experiences and life events. The fact is that the illness and suffering are firmly established in the ongoing life narrative so that they become a part of life, not only backward in time, but also in the present and in a possible future. The chronic fatigue becomes a shadow 
over earlier life events as well as over what is happening in the present and what the person believes will happen. It is, however, a shadow that the interviewees work with, and one they can perceive in several different ways; even things that could have happened exist there as shadows from the side. The use of different time shadows appears to have consequences for how issues like responsibility and freedom of liability emerge in the narratives. In that way the narrators can approach matters about blame, alternative actions, and hopes that can be of special significance in chronic illness that is contested.

Using different forms for temporalization means that we can negotiate and change the meaning of the relationship between events, and thus both the meaning of the course of events and the narrator him/herself as a character in his/her narration. The meaning and the significance in their own lives can thus be negotiated through temporalization by the interviewees who describe their lives from the perspectives of their illnesses. We argue that this makes it important to let the narrator's choice of temporalization become visible in the analysis and be treated as valuable data. If we neglect to regard the narrator's way of temporalizing his or her illness we will lose an important opportunity to understand specific aspects of the meaning of chronic illness.

Moreover, our analysis shows that people actually do also consider what could have happened. They use sideshadowing, not just in fictional works and historical novels, as shown by Morson and Bernstein, but also when people tell their own narratives of suffering. When what could have happened but never actually did happen is also pointed out in a narrative, it stands out in contrast to a more linear view of time and thus in contrast to the inevitability of backshadowing. However the question is if we, as researchers, tend to ignore in our analyses some of the sideshadowing that interviewees show in their narratives about illness, and are perhaps inclined to eliminate all the "loose ends" and create instead a neat, well-plotted story based on our own time concepts?

The interpretation of life experiences differs when time is seen as being predestined, or when, on the contrary, time is something that develops and can be influenced. For the person who receives a diagnosis for which there is a lack of images and narratives, the story is not a closed chapter but rather an ongoing one. Good and Good (1994) write that narratives about illness can, because of their structure, give an impression of incompleteness. Even though each narrative is organized into a beginning, a middle, and an ending, the narrator finds himself right in the midst of his/her own narration. The use of "time shadows" can be a way to tell about and to explain his/her illness. What has occurred up to the present can either be 
seen as something unavoidable that one should have understood a long time ago, or as something that was a possible result among many different ones.

In this way, time becomes less something that the narrators try to adapt to, and more of a resource they can use to help them understand and place their illness and suffering in a life perspective that is not limited solely to what has happened. Being still in the middle of one's own narrative, say Good and Good (1994), means that the end of the story is not given. It may possibly be so that the sideshadowing becomes more distinct because it is used to a great extent in ongoing narratives where shadows of what could have happened make it possible to keep the story open for several kinds of endings, and for handling questions of guilt and responsibility, of possibilities and hope. 


\section{REFERENCES}

Adam, B. (1995). Timewatch: The social analysis of time. Cambridge: Polity Press.

Asbring, P. (2001). Chronic illness - a disruption in life: Identity-transformation among women with chronic fatigue syndrome and fibromyalgia. Journal of Advanced Nursing, 34(3), 312-319.

Bakhtin, M. M. (1986). Speech genres and other late essays. Austin: University of Texas Press.

Becker, G. (1997). Disrupted lives: How people create meaning in a chaotic world. Berkeley: University of California Press.

Bernstein, M. A. (1994). Foregone conclusions. Berkeley, CA: University of California Press.

Brockmeier, J. (2000). Autobiographical time. Narrative Inquiry, 10(1), 51-73.

Bruner, J. (1986). Actual minds, possible worlds. Cambridge, MA: Harvard University Press.

Bruner, J. (2001). Self-making and world-making. In D. Carbaugh (Ed.), Narrative and identity: Studies in autobiography, self and culture (pp. 25-37). Amsterdam: John Benjamins Publishing Company.

Bury, M. (1982). Chronic illness as biographical disruption. Sociology of Health and Illness, 4(2), 167-182.

Bury, M. (2001). Illness narratives: fact or fiction? Sociology of Health \& Illness, 23(3), 263285.

Bülow, P. H. (2002). Sharing experiences of illness and suffering: Identity work and collectivised experiences. Manuscript submitted for publication.

Bülow, P. H., \& Hydén, L. C. (2003). Patient school as a way of creating meaning in contested illness: The case of CFS. health: An Interdisciplinary Journal for the Social Study of Health, Illness and Medicine, 7(2), 227-249. 
Charmaz, K. (1991). Good days, bad days: The self in chronic illness and time. New Brunswick: Rutgers University Press.

Davies, M. L. (1997). Shattered assumptions: time and the experience of long-term HIV positivity. Social Science \& Medicine, 44(5), 561-571.

Ezzy, D. (2000). Illness narratives: time, hope and HIV. Social Science \& Medicine, 50, 605617.

Fillmore, C. J. (1997). Lectures on deixis. Stanford: CSLI Publication.

Frank, A. W. (1995). The wounded storyteller: Body, illness, and ethics. Chicago: The University of Chicago Press.

Freeman, M. (1993). Rewriting the self: History, memory, narrative. New York: Routledge.

Freeman, M. (1998). Mythical time, historical time, and the narrative fabric of the self. Narrative Inquiry, 8(1), 27-50.

Gee, J. P. (1986). Units in the production of narrative discourse. Discourse Processes, 9, 391422.

Gee, J. P. (1991). A linguistic approach to narrative. Journal of Narrative and Life History, 1(1), 15-39.

Gergen, K. J., \& Gergen, M. M. (1986). Narrative form and the construction of psychological science. In T. R. Sarbin (Ed.), Narrative psychology: The storied nature of human conduct (pp. 22-44). New York: Preager Publishers.

Goffman, E. (1961). Encounters. Two studies in the sociology of interaction. Indianapolis: The Bobbs-Merrill.

Good, B. J., \& Good, M.-J. D. V. (1994). In the subjunctive mode: Epilepsy narratives in Turkey. Social Science and Medicine, 38(6), 835-842.

Goodman, N. (1981). Twisted tales; or, story, study, and symphony. In W. J. T. Mitchell (Ed.), On narrative (pp. 99-115). Chicago: The University of Chicago Press. 
Herman, D. (1999). Toward a socionarratology: New ways of analyzing natural-language Narratives. In D. Herman (Ed.), Narratologies: New perspectives on narrative analysis (pp. 218-246). Columbus: Ohio State University Press.

Hydén, L. C. (1995). The rhetoric of recovery and change. Culture, Medicine and Psychiatry, 19, 73-90.

Hydén, L. C. (1997). Illness and narrative. Sociology of Health \& Illness, 19, 48-69.

Labov, W. (1972). Language in the inner city. Philadelphia: University of Pennsylvania Press.

Labov, W. (1982). Speech actions and reactions in personal narrative. In D. Tannen (Ed.), Analyzing discourse: Text and talk (pp. 219-247). Washington, DC: Georgetown University Press.

Mattingly, C. (1998). Healing dramas and clinical plots: The narrative structure of experience. Cambridge: Cambridge University Press.

Melucci, A. (1996). The playing self: Person and meaning in the planetary society. Cambridge: Cambridge University Press.

Mishler, E. (1992). Work, identity, and narrative: An artist-craftsman's story. In R. L. Ochberg (Ed.), Storied lives: The cultural politics of self-understanding (pp. 21-40). New Haven, CT: Yale University Press.

Mishler, E. G. (1999). Storylines: Craftartists' narratives of identity. Cambridge, MA: Harvard University Press.

Morson, G. S. (1994). Narrative and freedom: The shadows of time. London: Yale University Press.

Nussbaum, M. C. (1986). The fragility of goodness. Luck and ethics in Greek tragedy and philosophy. Cambridge: Cambridge University Press.

Orona, C. J. (1990). Temporality and identity loss due to Alzheimer's disease. Social Science \& Medicine, 30, 1247-1256. 
Pierret, J. (2001). Interviews and biographical time: The case of long-term HIV nonprogressors. Sociology of Health \& Illness, 23(2), 159-179.

Riessman, C. K. (1990). Divorce talk: Women and men make sense of personal relationships. London: Rutgers University Press.

Robinson, I. (1990). Personal narratives, social careers and medical courses: Analysing life trajectories in autobiographies of people with multiple sclerosis. Social Science and Medicine, 30(11), 1173-1186.

Williams, G. (1984). The genesis of chronic illness: Narrative re-construction. Sociology of Health and Illness, 6(2), 175-200.

Williams, G. (1993). Chronic illness and the pursuit of virtue in everyday life. In A. Radley (Ed.), Worlds of illness (pp. 92-108). London: Routledge.

Young, K. (1989). Narrative embodiments: Enclaves of the self in the realm of medicine. In K. J. Gergen (Ed.), Texts of identity (pp. 152-165). London: Sage. 